\title{
Field experiments on "living" snow fences
}

\author{
Florence Naaim-Bouvet, ${ }^{1}$ Pierre Mullenbach ${ }^{2}$ \\ ${ }^{1}$ Division Nivologie, CEMAGREF, Domaine universitaire, BP 76, 38402 Saint-Martin-d'Hères Cedex, France \\ ${ }^{2}$ Division Ecosystèmes et Paysages Montagnards, CEMAGREF, Domaine universitaire, BP 76, 38402 Saint-Martin-d'Hères Cedex, France
}

\begin{abstract}
In France, drifting snow is generally controlled using artificial snow fences. Living snow fences are not a new concept but they have only been used on a limited scale. Research directly related to natural plant barriers is limited. We therefore decided to study the behaviour of species that would survive and grow satisfactorily in the French Alps.

In the first experiment, we compared the storage capacity of several different kinds of living fences consisting of pruned spruces, unpruned spruces and sorbs.

Field observations during the winter of 1995-96 proved that deciduous trees such as sorbs are effective, and that pruning the lower $50 \mathrm{~cm}$ is not effective at the end of the season because of the weight of snow on low branches.

However, the use of natural plant barriers has disadvantages: a living snow fence takes time to reach an effective height and is difficult to establish on windy sites at a high altitude. This is a real problem. Therefore, in a second experiment, we studied the death rate of larches planted behind a fence. We noticed that the snow fence had several effects, snow accumulation (until the planted trees grew up) and protection of the planted trees.
\end{abstract}

\section{INTRODUCTION}

Drifting snow creates problems which have several practical effects in France:

Formation of cornices (and consequently potential avalanche hazard).

Poor snow depth on skied crests in resorts.

Formation of snowdrifts on roads (causing disturbance to communications and transportation).

In 1991, we carried out a survey of drifting snow control in France. The replies of local branches of the Road Administration to queries showed that the methods of dealing with snowdrifts were:

Snow clearing $(77 \%$ of replies).

Snow fences ( $14 \%$ of replies).

Planting trees ( $7 \%$ of replies).

Modification of road profiles ( $2 \%$ of replies).

Snow clearing took priority and planting trees accounted for only $30 \%$ of preventive measures, often through lack of money. But this survey concerned only provincial and interprovincial roads.

In recent years, the use of windbreaks to control drifting snow has become widespread, because the landscape has been taken into account in new road projects. Planting trees is consequently likely to develop. Living snow fences are not a new concept: in Germany, they appeared as early as 1852 along railroads (Nordling, 1864). But they have only been used on a limited scale. Research directly related to natural plant barriers (unlike artificial snow fences) is limited (Shaw, 1988). We therefore decided to study the behaviour of species that would survive and grow satisfactorily in the French Alps. The aim of the first experiment presented in https://doi.org/10.3189/1998AoG26-1-217-220 Published online by Cambridge University Press this paper was to compare the storage capacity of several different kinds of living snow fence. However, using windbreaks poses problems because natural plant barriers take time to reach an effective height and are difficult to establish on windy sites at high altitudes. Therefore, in a second experiment, also presented in this paper, we studied the effect of an artificial windbreak on the growth of trees planted in an Alpine area subject to drifting snow.

\section{EFFECT OF NATURAL PLANT BARRIERS ON SNOW-DISTRIBUTION PATTERNS}

\section{Field site}

Windbreak hedges operate in the same way as artificial snow fences. Previous studies (Martinelli, 1973; Tabler, 1980) have shown that the largest storage capacity is achieved by a $50 \%$ porous fence with a bottom gap. We therefore conducted research on deciduous trees and on pruning of the low branches of the hedges.

In 1991, we planted strips consisting of:

20 pruned spruces, $1.7 \mathrm{~m}$ high (with a "bottom gap" of $50 \mathrm{~cm}), 1 \mathrm{~m}$ apart.

20 unpruned spruces, $1.7 \mathrm{~m}$ high, $1 \mathrm{~m}$ apart.

60 sorbs, $1.7 \mathrm{~m}$ high, $0.33 \mathrm{~m}$ apart.

The hedge was clipped every year to maintain a constant height.

We completed the strip with an artificial snow fence $1.7 \mathrm{~m}$ high, with $50 \%$ porosity and a bottom gap of $50 \mathrm{~cm}$. This type of wood fence with horizontal slats is usually used to keep snowdrifts off roads. Its design features are optimal (i.e. they maximize snow storage) and it could be considered as a reference fence. 
The fences were set at right-angles to the prevailing wind and located on flat terrain at an altitude of $1200 \mathrm{~m}$. (Manse Pass) (Fig. 1), so that the terrain exerted negligible influence. The site is well exposed to sunlight, average annual precipitation is $1200-1300 \mathrm{~mm}$ and annual mean temperature ranges from $6^{\circ}$ to $7^{\circ} \mathrm{C}$.

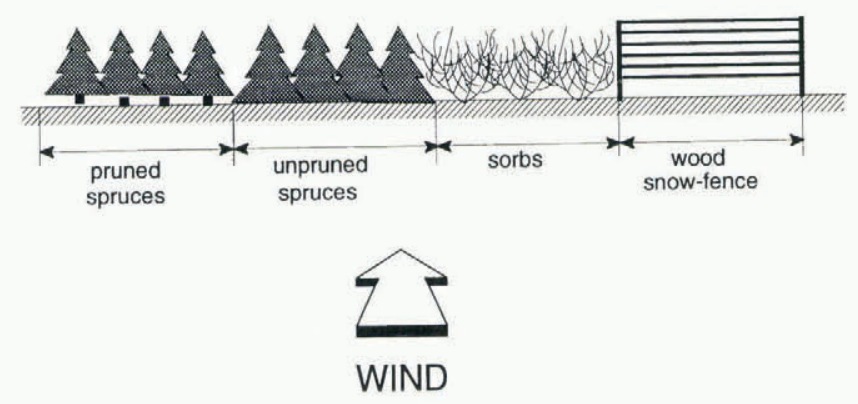

Fig. 1. Field site at Manse Pass.

\section{Porosity of windbreaks}

Although the drag coefficient is more appropriate for predicting snow fence drifts, the porosity ratio, i.e. the fraction of openings to frontal area perpendicular to the wind, allows us to characterize the snow fence's operation.

The porosity of plant barriers was estimated using image processing. Image analysis produced average porosity or vertical porosity profiles. Sorbs have a homogeneous porosity of about $50 \%$. Spruces have an average porosity of about $35 \%$, the top of the hedge has a porosity of more than $70 \%$, whereas the base has a porosity of $30 \%$.

\section{Experimental results}

The basic measurement made to assess the efficiency of hedges is the measurement, using snow poles, of the average volume of snow collected after every snow storm. Measurements were carried out on a median line perpendicular to the barriers. Field observations were conducted during the winter 1995-96. During this winter, the wind was particularly fierce and the upwind drifts were inconsiderable.

After the first snow storm, the artificial snow fence (Fig. 2 ), considered as a reference snow fence, appeared to be the least efficient of all the barriers. This may be due to the strong wind blowing when drifting snow occurs; this optimum snow fence geometry was designed for a wind of medium intensity.

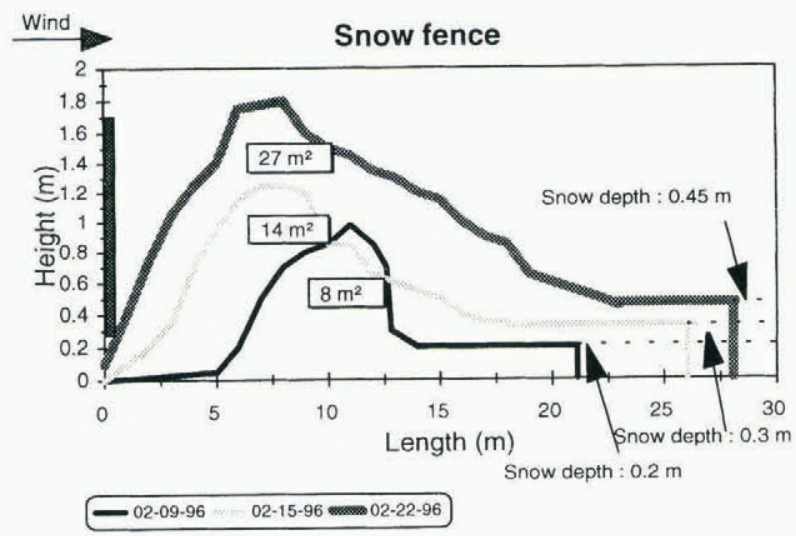

Fig. 2. Snow-distribution pattern of an artificial snow fence

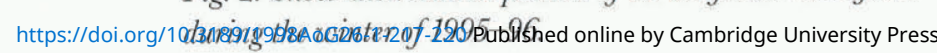

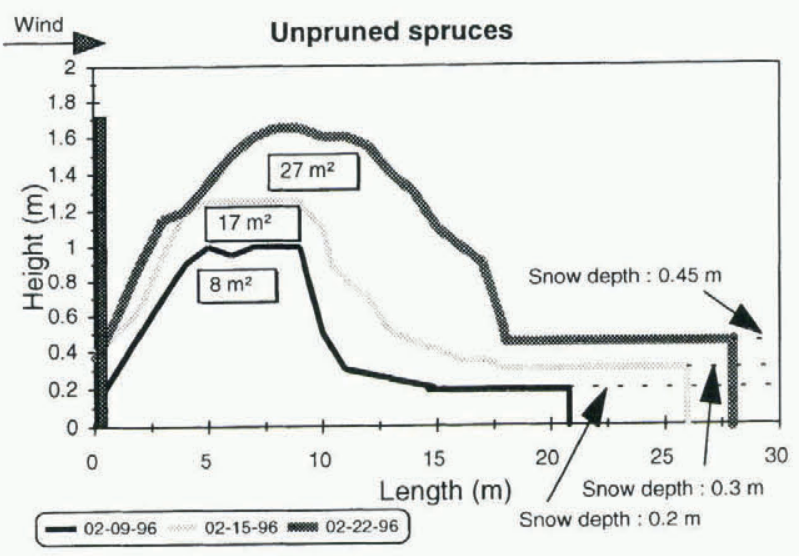

Fig. 3. Snow-distribution pattern of an unpruned spruce windbreak during the winter of 1995-96.

According to the field data, the "bottom gap" of the pruned spruces has an important effect on drift shape: during the first snow storm, the pruned spruce windbreak created a lower, longer drift away from the windbreak (Fig. 3). But, at the end of the season pruning of the lower $50 \mathrm{~cm}$ was no longer effective (Fig. 4) because of the weight of snow on the lower branches and there was no longer a bottom gap.

In order to compare the collection efficiency of the

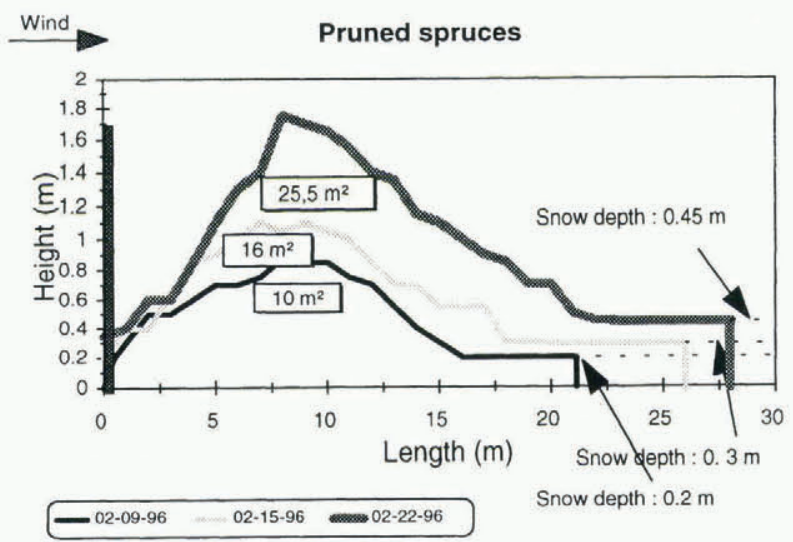

Fig. 4. Snow distribution pattern of a pruned spruce windbreak during the winter of 1995-96.

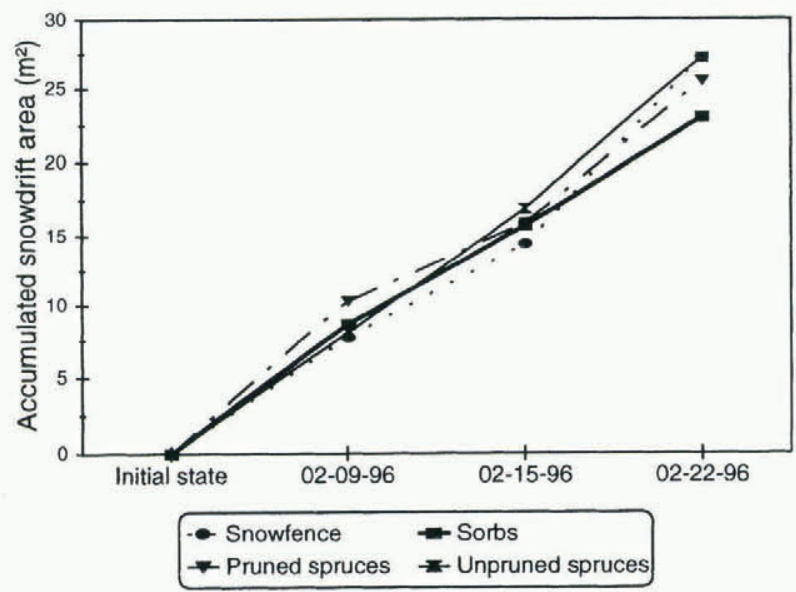

Fig. 5. Development of snow storage as a function of time. 
different hedges, it is necessary to use the same reference length. We have chosen 21, 26 and $28 \mathrm{~m}$, corresponding to the maximum length of the snowdrifts respectively observed on 9,15 and 21 February 1996.

In this way, we obtained the values shown in Figures 5 and 6. But, if the only snow depth to be taken into account is the overload due to the obstacle, these values are modified (Figs 7 and 8).

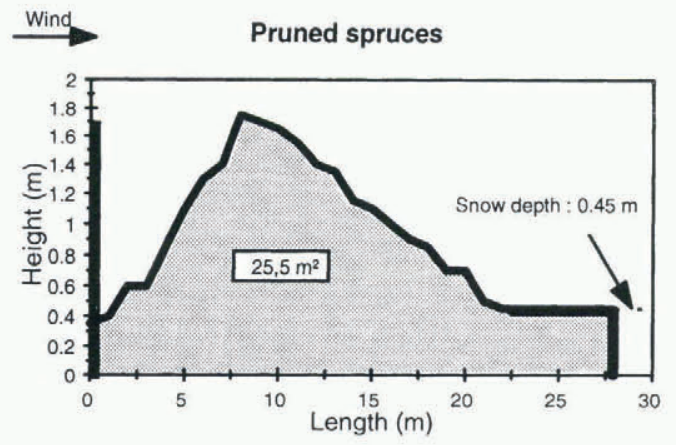

Fig. 6. Accumulated snowdrift area taken into account in Figure 5.

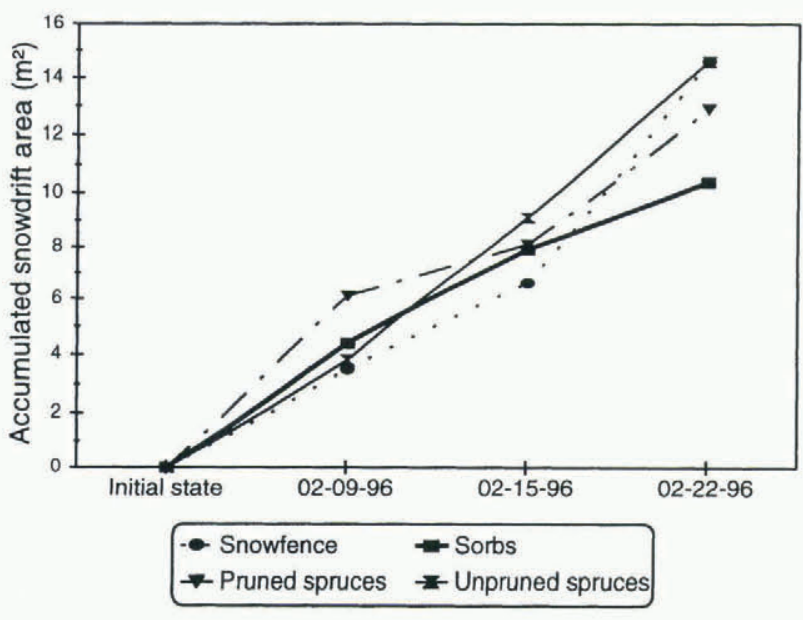

Fig. 7. Development of snow storage as a function of time.

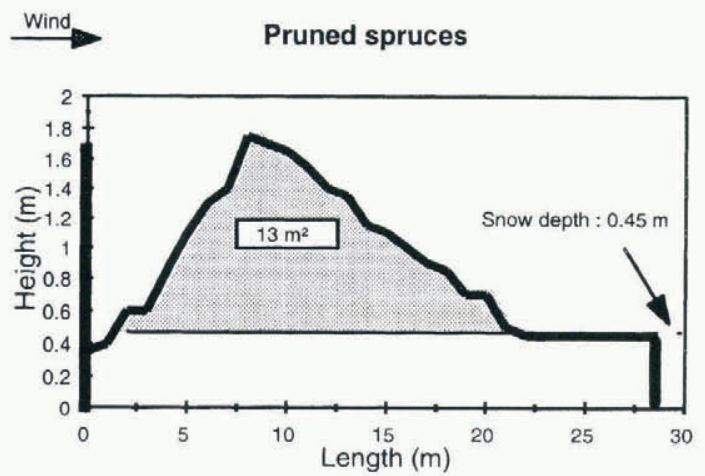

Fig. 8. Accumulated snowdrift area taken into account in Figure 7.

Unpruned spruces seem to be as effective as a snow fence. As for deciduous trees such as sorbs (Fig. 9), it may be observed that they are effective since their snow-collection efficiency is about $80 \%$ of the artificial snow-fence's collection efficiency (Figs 5 and 7) at the end of the season. Decid- uous trees fit better in with the landscape, especially in areas where trees like spruces are unusual.

Despite the great diversity of drift shape, the snowstorage capacity is approximately the same for each windbreak; the difference between the storage capacity is about $20 \%$. Nevertheless, it should be stressed that equilibrium drifts have not been achieved.

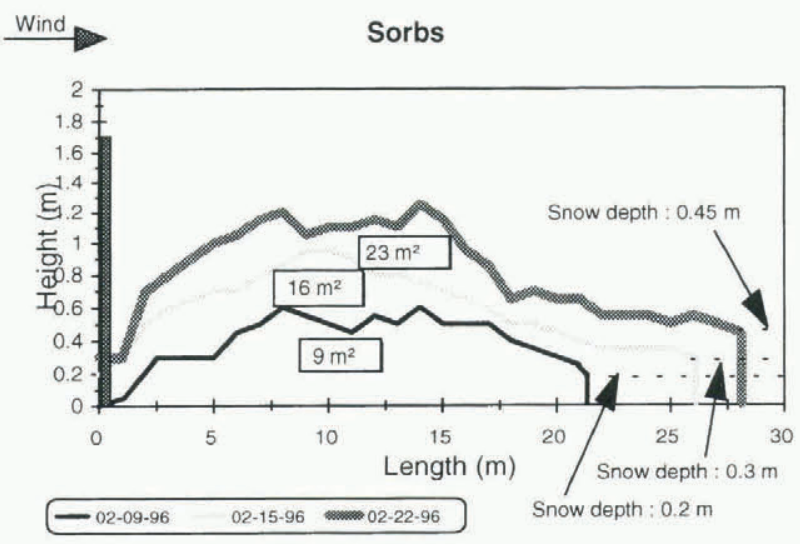

Fig. 9. Snow-distribution pattern of a sorb windbreak during the winter of $1995-96$.

\section{ESTABLISHMENT OF LIVING SNOW FENGES}

Nonetheless, the use of natural plant barriers has disadvantages: a "living" snow fence takes time to reach an effective height (it is expensive to plant tall windbreaks) and they are difficult to establish on windy sites at a high altitude. The solution to this problem could be the erection of a snow fence, as the following experiment proves.

\section{Field site}

About 10 years ago, ten rows of 50 larches were planted $0.5 \mathrm{~m}$ apart leeward of a chestnut fence $1.1 \mathrm{~m}$ high with a bottom gap $(0.1 \mathrm{~m})$ and with $50 \%$ porosity on a windy site (Chazelet) subject to drifting snow at an altitude of $1900 \mathrm{~m}$. The death rate of larches planted behind a fence was studied.

\section{Experimental results}

Between 0 and $22 \mathrm{~m}$, the death rate is low (from zero to $35 \%$ ). But beyond $22 \mathrm{~m}$, the death rate increases significantly from 50 to $100 \%$ (Fig. 10).

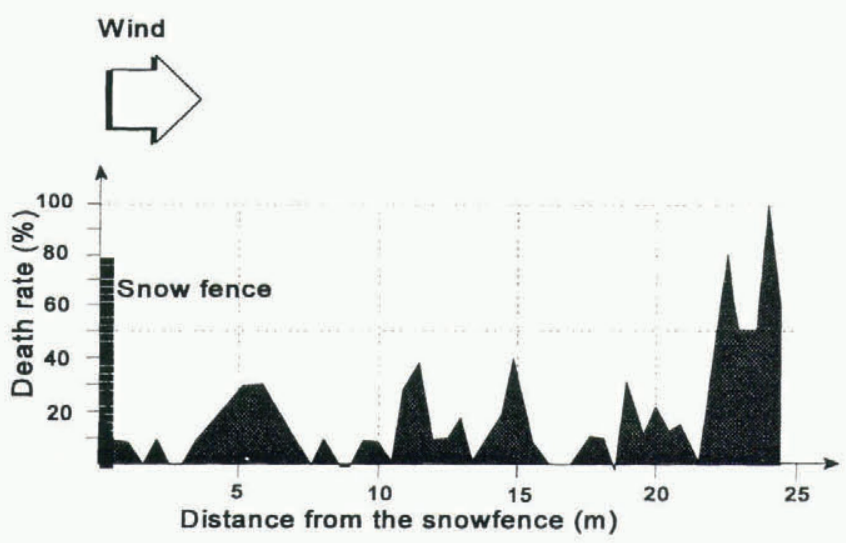

Fig. 10. Larch death rate as a function of the distance downwind from the fence (Mullenbach, 1987). 
This is due to the wind-speed reduction leeward of the fence. The reduction of the area protected from the wind is proportional to the height $(H)$ of the shelter. A reduction of $20 \%$ may extend about $20 H$ from the windbreak, which corresponds to the observed boundary between a low death rate and a high death rate. Moreover, this distance corresponds approximately to the length of the snowdrift generated by a chestnut snow fence (Brugnot, 1989).

In the absence of snow, the snow fence acts as a windbreak. In cold climates, a windbreak may cause an average increase in plant temperature and a rather slight increase in photosynthesis and may limit physical damage caused by the wind (Grace, 1988). When blowing snow occurs, snowdrifts form leeward of the snow fence, providing additional soil moisture (Scholten, 1988) and protecting planted trees against the frost. But the influence of the snowdrift on plant growth might be positive or negative, depending on the height of the deposit. If this height is greater than 1.5 or $2 \mathrm{~m}$, plants are crushed and both branches and trunks may be broken. Moreover, if the duration of the snow coverage is too long in the spring, fungi destroy the needles and branches. Snow deposit must be spread uniformly as far as possible. That is why it is not really advisable to erect a snow fence without a bottom gap, with a small porosity ratio or with a height $>1 \mathrm{~m}$.

Benefits from snow-fence erection were measured by comparing yields from protected and unprotected zones. In this way, we observed that a snow fence had several effects:

Snow accumulation (until planted trees grow up)

Protection of planted trees (the death rate increases distinctly from 50 to $100 \%$ when larches are planted more than $22 \mathrm{~m}$ away from the snow fence).

\section{CONCLUSIONS AND PERSPECTIVES}

According to the field data, deciduous trees such as sorbs make it possible to obtain sizeable snowdrifts, because the snow-storage capacity is about $80 \%$ of the artificial snow fence's storage capacity at the end of the season. Contrary to expectations, pruning of the low branches is not really ef- fective because of the weight of snow on the lower branches. But in a general way, "living" snow fences give good results for protecting roads or buildings against snowdrift formation. When planting, it is advisable to install snow fences windward of a hedge. This snow fence serves a double purpose. Not only does it protect roads or buildings against snowdrift formation until the planted trees grow up, but it also protects these trees.

The porous snow fence's height does not need to be more than approximately $1.5 \mathrm{~m}$, otherwise branches and trunks can be broken by the pressure of snow. Because of this low height, it might be necessary to install several rows of snow fences in order to protect roads or buildings before planted trees are effective. The first results are encouraging. But only two species have been studied and we have not taken into account the influence of the use of sodium chloride and other salts for de-icing roads on the tested hedges. Furthermore, clipping hedges modifies the porosity ratio and it would be necessary to study their evolution. A better understanding of the behaviour of living snow fences requires additional research in the field.

\section{REFERENCES}

Brugnot, G. 1989. Six years of snow-fence testing in France. Ann. Glaciol., 13, $16-19$.

Grace, J. 1988. Plant response to wind. In Brandle, J. R., D. L. Hintz and J.W. Sturrock, eds. Agriculture, ecosystems and environment. Vol. 22/23. Amsterdam, Elsevier, 71-88.

Martinelli, M., Jr. 1973. Snow-fence experiments in alpine areas. 7. Glaciol., 12(65), 291-303.

Mullenbach, P. 1987. Étude des reboisements daltitude, résultats expérimentaux. Grenoble, Centre d'Étude de Machinisme Agricole, du Génie Rural, des Eaux et des Forêts. (Rapport interne.)

Nordling, M. 1864. Sur les moyens de prévenir les amoncellements de neige sur les chemins de fer. Annales des Ponts et Chaussées, 105(10), 1-17.

Scholten, H. 1988. Snow distribution on crop fields. In Brandle, J. R., D. L. Hintz and J. W. Sturrock, eds. Agriculture, ecosystems and environment. Vol. 22/ 23. Amsterdam, Elsevier, 363-380.

Shaw, D. L. 1988. Design and use of living snow fences in North America. In Brandle, J. R., D. L. Hintz and J.W. Sturrock, eds. Agriculture, ecosystems and environment. Vol. 22/23. Amsterdam, Elsevier, 351-362.

Tabler, R. D. 1980. Geometry and density of drifts formed by snow fences. 7 . Glaciol., $26(94), 405-419$. 